\section{An Analysis of Participation, Identity Conversations, and Social Networking Affordances on an Online Social}

\section{Network for Children}

\section{Stephanie Valentine}

Sketch Recognition Lab,

Department of Computer Science \& Engineering,

Texas A\&M University

valentine@tamu.edu

\section{Tracy Hammond}

Sketch Recognition Lab,

Department of Computer Science \& Engineering

Texas A\&M University

hammond@tamu.edu

\section{ABSTRACT}

In this study, we explore the behaviors of children ages 7 to 12 years on our custom social network, KidGab, to understand the activities that increase participation and identity-related conversation. We specifically study the effects of two social networking affordances provided by KidGab: a suite of personality quizzes and a badge-based participatory reward system. Both affordances harness the preadolescent's internal focus on identity exploration. We analyzed KidGab's activity logs in an attempt to understand the relationships between activities on these affordances and other engagement measured on the site (e.g., the total posts authored on KidGab per day, total comments authored per day, likes per day, etc.). We also investigate the amount of conversation relating to identity that accompanies quizzes and badges. We found that taking quizzes and posting results had a higher positive correlation with online participation on KidGab than attempting to earn badges. Our results suggest that, though youth are interested in selfreflecting via textual compositions, on a daily basis they partake more in personality-quiz-style activities that provide them instant feedback and shared experiences with other users.

\section{KEYWORDS:}

Social networking; Child-computer interaction; Humancomputer interaction; Identity exploration

The Journal of Media Innovations 3.1 (2016), 41-62.

DOI: http://dx.doi.org/10.5617/jmi.v3i1.2516

http://www.journals.uio.no/index.php/TJMI

(c) Stephanie Valentine and Tracy Hammond 2016. 


\section{INTRODUCTION}

Today's youth are online. In fact, to many youth, their identities are not proven to exist without an online presence in the form of an online social networking profile or blog (Stern, 2008). Many researchers in the last decade have attempted to understand how teens act and behave online, what interests them, and what they like and dislike (boyd, 2008; boyd, 2004; Donath \& boyd, 2004; Goodstein, 2007; Hinduja \& Patchin, 2008; Itō et al., 2010; Willett, Robinson, \& Marsh, 2009; O'Keeffe \& Clarke-Pearson, 2011). Boyd, for example, conducted a two-year ethnographic study on teens and their motivations and behaviors on social networks (boyd, 2008). Boyd found that connectivity to musicians and celebrities, public connectivity to acquaintances and friends, and finding a balance between uniqueness and conformity in public identities motivated users to participate on Myspace. Clarke (2009, p. 22) posited that social networking sites provide "young adolescents a sense of agency and encourages them to take responsibility for shaping their own development.” Itō suggested that online social networking for teens encourages a sense of solidarity and a space for teens to get recommendations from peers about what televi- sion shows to watch, what music is worth listening to, what to wear, what to like, etc. (Itō et al., 2010). This sampling of researchers' conclusions about youth social network users all echo a common theme - that social networks provide youth a space to explore their identities.

This collection of work is vast and compelling but has several limitations. First, most studies regarding motivations and behavior of online youth typically consider a teenage population; there is very little published research regarding how and why preadolescent children (ages 7 to 12 years) participate on online social networks. Secondly, each of the above-mentioned studies describes social networking behaviors from the self-reported perspective of the youth social networker herself. Bauman and Tatum define social networking as the co-creation of interactive communications, by the users and by the platform (S. Bauman \& Tatum, 2009). In the above works, there is a valuable perspective missing from the analyses: the perspective of the social networking platform. The platform contains the complete record of actions and communications made by a user every nanosecond of every day. Only a few researchers have designed social networks for children (Abeyrathne et al., 2011; Joshi \& Walsh, 2011; Näsänen, Oulasvirta, \& Leh- muskallio, 2009; Wärnestål \& Nygren, 2013) and even fewer have actually developed and deployed such a system to understand how children interact with it (Inkpen, Du, Roseway, Hoff, \& Johns, 2012; Winn, 2012).

To address this chasm in published knowledge regarding the actual behaviors of preadolescent children online, we designed, developed, and deployed a social network of our own: KidGab. KidGab is a private social network for preadolescents to learn expressive and safe social networking habits before they reach the age of 13 years, the age at which one can legally join most adult social networks. In this work, we analyze the self-presentation and identity-related behaviors recorded on KidGab, specifically in reference to the common affordances of personality quizzes and rewarded topic-based posting (our badge system). Youth say they are motivated to maintain online profiles because it is a means of self-reflection (boyd, 2008), yet they simultaneously crave meaningful feedback from their peers (Stern, 2008). Does the artificial feedback acquired from personality quiz results overpower the desire for self-reflection? Previous work examines and relays youth social networking users' overall objectives, but this work explains what youth actually do on online social networks. 


\section{BACKGROUND}

This study focuses around two major concepts and their relationships with youth and digital media: identity and self-presentation. In this section, we explore the foundational works upon which we have based the definitions and methodologies presented in this work.

Identity is an overloaded term, defined differently by researchers of various fields, especially in the context of youth and adolescents. Is identity a thing or a process (Bauman, 2008)? Are youth merely "becomings" - compilations of adult influences - or are they "beings" in their own right (Buckingham, 2008)? Buckingham's (2008) "Introducing Identity" provides an extensive review of a myriad of perspectives on definitions identity with respect to youth and digital media. For the purposes of this study, we define identity according to Larson's (1995) view: one's identity is "a personal iconography of values, symbols, and identifications that answer the question, 'Who am I?"'. To this, we add an experiential component. One youth blogger interviewed by Stern (2008) mused that her blog (her online identity) is a chronicle of who she is, what she has experienced, and how she feels about it. In the same work, Stern presents an argu- ment that the analysis of online cultural production should be done from the vantage point of the youth, rather than from the adult standards of evaluation which may be inappropriate for youth subjects. As such, we consider this view of youth digital identity, astutely provided by a member of the digital youth population, as an appropriate addition to Larson's "analog" definition of identity.

The second concept paramount to this work is that of self-presentation. Classically, self-presentation is defined as a process through which a person constructs every external interaction, each utterance and action, into a carefully constructed presentation for an audience, usually with the intention of eliciting approval (Goffman, 1959). This view of self-presentation brings about two corollary concepts crucial to the discussion of digital identity and youth. Firstly, in the context of digital participation, we must consider that every digital artifact is made with an audience in mind (be it the self, close friends, or the world) (boyd, 2008; Stern, 2008). Second, we must remember that the predominant motivation of such utterances and actions is to elicit the approval of others (Stern, 2008). Buckingham united the concepts of self-presentation and identity among digital youth with a simple statement, "Identity is developed by the individual, but it has to be recognized and confirmed by others" (Buckingham, 2008, p. 5).

Youth have described their self-presentations on social media as attempts at appearing cool (as defined by the target audience's perception of cool), introspective, witty, or alternative (specifically in respect to musical tastes) to the audiences they target (boyd, 2008). Over time, as youth develop this chronicle of audience-targeted self-presentations, youth effectively "write themselves into being”(Addison \& Comstock, 1998, p.129). This being, authored by an individual for an audience, ultimately seeks acceptance from that audience. Indeed, social approval in the form of positive feedback is the primary motivator for using digital media as a "chronicle" of one's identity (Stern, 2008). During adolescence, youth begin to increase their concern for conformity, fitting in, and not feeling alone. In this time, the desire for feedback (in the form of site visits, likes, guest books, comments, etc.) from members of their actual or desired peer group is intense (Stern, 2008). Such feedback reassures the youth that they are valued and that they are not alone.

Modern social networks for youth share many common affordances: avatars, "about me" areas, textual posting, comments, friends lists, topic- 
based posting (sometimes motivated by digital badges), and personality quizzes. How is each of these theoretically motivated? Photographic or cartoon avatars allow youth to strategically refine others' perceptions of their body and the role they intend to play in society (Turkle, 1995). Textual posting and "about me" sections provide vehicles through which youth can directly author and revise their self-presentations (Addison \& Comstock, 1998: boyd, 2008) by chronicling their feelings and experiences. Comments form the foundation of social discussion and provide youth the feedback they so acutely desire (Stern, 2008). Friends lists play the vital role of concretely depicting one's peer group. Some of the most important self-presentations on a youth's digital media page are the connections with others because they believe in some respects "they are who they know" (boyd, 2008). Friends lists provide evidence of the social categories they fit into, and each connection can be seen as a sort of endorsement (Donath \& boyd, 2004; Itō et al., 2010), thus catering to youth's desire for approval and feedback. Youth interactions with each of these features of modern digital media have been studied in detail via qualitative methods (particularly via ethnographic methods).
The two social networking affordances discussed in this work are much less-studied: topicbased posting (as motivated by a digital badge system) and personality quizzes. Topic-based posting, informally described as participating in popular digital cultural movements (e.g. posting opinions regarding popular political/media topics using a predefined hashtag) appeal to youth's desire to use social media as a tool of self-reflection (Buckingham, 2008; Stern, 2008). By writing out feelings, one grows to better understand how he or she feels (Stern, 2008). Occasionally such topic-based posting behaviors are rewarded via digital badges (Antin \& Churchill, 2011), which can in turn be used to represent a user's clout in the digital community (Halavais, Kwon, Havener, \& Striker, 2014). This practice of topic-based posting involves some risk, however, because adding original thoughts to a movement of pre-existing opinions and experiences allows for disagreement and unrelatableness two effects contrary to the goals of acceptance and conformity carried by youth (Stern, 2008). Youth seek feedback from people who can relate to them, feedback that validates their opinions and identities (boyd, 2008). Such feedback is not likely to appear when the youth's peers cannot relate to the ideas expressed in the post.
Personality quizzes allow youth to explore their own identities and receive concrete descriptions of their personalities (for them to agree with or disagree with in turn) (boyd, 2008). This concrete description, in the context of a community whose members have likewise taken the quiz, allows youth to see clearly how they are the same as others and how they are different. Personality quizzes offer three advantages and allures. Firstly, they could be considered an artificial but very concrete form of the positive and individualized peer feedback that youth so intensely crave. Secondly, self-presentation in the form of personality quiz results generally lacks the social risks of disapproval and unrelatableness seen in self-authored digital artifacts (such as those for topic-based postings); the responsibility for authorship of the personality description is offloaded to the author of the quiz. As such, personality quiz results could be seen as a less risky starting point for discussions and self-

1 Some researchers use the word "experiment" to describe the way in which youth try out different opinions and characteristics in the quest to define themselves. We use the word "explore" because youth object to the term "experiment". They feel it implies their statements and self- presentations are in some way inauthentic (Stern, 2008). 
presentations. Third, the acts of taking a quiz and posting quiz results provide youth a shared experience to discuss. Shared experiences serve as the foundation for conversation in both online and offline situations (H. H. Clark, 1996; Erickson \& Kellogg, 2000).

In this work, we investigate the motivations of topic-based badge systems and personality quizzes and their relationships to overall online participation on social networks for youth. We define online participation as the quantitatively measurable collection of activities recorded by an online social networking platform, such as logins, posts, comments, likes, taking quizzes, and earning badges.

\section{THIS WORK}

This work is unique in many ways. We conduct our analyses on data collected from our own, customdesigned social network for children, KidGab. We have access to every activity completed by the users: complete user profiles, extended metadata, and a clear understanding of the activities occurring across the entire network at all times. Additionally advantageous, we have the ability to manipulate circumstances in order to understand the impacts of specific events on participation. For example, we have full control over the release times for personality quizzes, which allows us to study the effects of timing on participation.

Secondly, as mentioned above, very little research in social networking investigates online behavior of children due to the legal complications involved with data collection and parental consent. Because we manage the network ourselves, we are able to obtain appropriate consent and assent both to participate in research and to collect online data about our child users. Only children who themselves assent to participate and whose parents likewise consent to their participation are allowed access to our social network.

Provided the wealth of data including user reactions to stimuli we introduce on the network, we chose to study and understand which of our affordances (badges or quizzes) actually resulted in more community participation. Specifically, we study whether badge systems or personality quizzes garner more prevalent activity and whether these stimuli correlate with an increase in conversation about identity.

\section{RESEARCH QUESTIONS AND HYPOTHESES}

In this study, we sought to answer several questions comparing badge-earning and quiz-taking behaviors. Do youth choose to engage with one affordance more frequently than the other? Does engaging with one affordance increase overall site participation more than the other? Which induces more discussion of identity? Which desire is stronger; the desire for feedback (quizzes) or the desire for self-reflection (badges)?

To answer these questions, we test four hypotheses:

1. There exists a significant positive correlation between online participation and the taking and posting of personality quizzes among preadolescent girls.

Rationale: Personality quizzes are a low-risk and shared-experience starting point for communication and engagement with (as well as relating to and learning about) other members of an online community. "You got Gryffindor? I got Ravenclaw!" Such simple interactions forge the pathway to more interactions, and, as a result, participation grows. 
2. There exists a significant yet weaker positive correlation between badges and online participation of preadolescent girls.

Rationale: Sharing opinions and experiences surrounding predefined topics is an attractive activity for self-reflection, but the risks of disapproval and unrelatableness for both the author and potential commenter make it less likely to spur more participation than personality quizzes.

3. Personality quizzes encourage online discussions of identity among preadolescent girls on social networks.

Rationale: Given Hypothesis 1, it follows that the riskiest discussions - those that have the potential to elicit identity-threatening disapproval from peers - might be best started in relatively safe places.

4. Badges also encourage online discussion of identity among preadolescent girls but to a lesser degree than do personality quizzes.

Rationale: The social risk associated with agreeing or disagreeing with a person makes it less likely to be a starting-point for discussion, especially when the discussion regards a sensitive topic like one's identity.

\section{METHOD}

KidGab

We test each of these hypotheses using data collected on KidGab. KidGab is a custom social network for children aged 7 to 12 years. We designed and built KidGab as a means of studying social networking behaviors of children from the inside out. KidGab features most basic social networking affordances, including unrestricted textual posting, unrestricted textual commenting, image upload, "like" functions, groups, chat rooms, etc. Figure 1 displays a sample profile page on KidGab. We specifically designed KidGab to include few restrictions, rather to enable children the freedom to express themselves and learn safe social networking habits through mentored and monitored practice. Parents and researchers frequent the network to ensure users are behaving safely and respectfully. In the case a researcher or parent finds a post or be- havior to be unsafe or disrespectful, ${ }^{2}$ he or she can address the situation with the relevant users in a calm and educational manner. KidGab is intended for use in small communities of children (schools, sports teams, scouting troops, youth groups, etc.) as a medium through which to practice digitizing existing friendships and to keep organizations connected.

KidGab provides an extensive collection of cartoon-like avatar-creation components that allows users to express and explore their identities. The avatars also serve another purpose: avatars provide children a fun alternative to uploading photographs of themselves to their profiles, a practice that is considered dangerous for children of this age for multiple reasons: because it may cause them to be targeted by pedophiles (Posey, 2002), because

2 To our knowledge, there has only been one instance of disrespectful behavior that needed to be addressed on KidGab. Two girls employed several swear words in a chat room. Site administrators informed the girls that the behavior was not acceptable in the KidGab community and that all future activities should remain "fun but Girl Scout appropriate." The girls continued to be active on KidGab and such behavior never occurred again 


\section{KIOGaO}

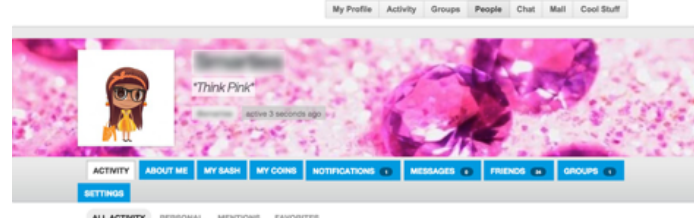

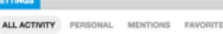

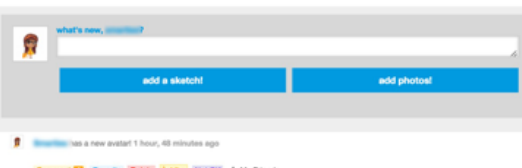

C

2:

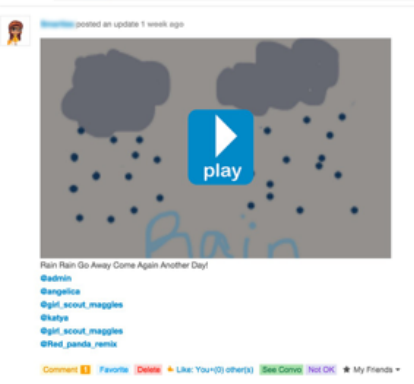

ด

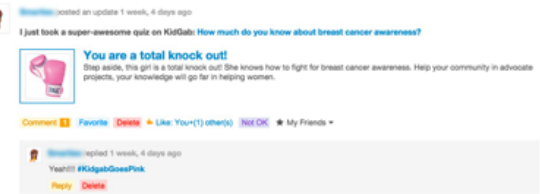

Figure 1: Example of a user's profile page. Usernames are blurred to maintain the user's privacy. it may cause them to be victims of identity theft (particularly for acquiring passports) (Sullivan, 2008), and because of the rampant sexualization displayed by young girls in photographic profile images (Ringrose, 2010). The profile page in Figure 1 includes an avatar in the top left corner.

Beyond avatars, another social networking affordance for self-expression offered by KidGab is sketch-based posting. Users can sketch images using KidGab's sketch interface and post their artistic masterpieces to their own or their friends' walls. Figure 1 includes a sketch of rainclouds posted by one of KidGab's users. As hinted by the triangular "play" button atop the sketch, KidGab's sketches are not stored as mere images; rather they are stored as short videos that replay the sketch composition from start to finish. This sketch playback allows for multi-scene storytelling and simple animations.

Most important to this study are the social networking affordances for gamified topic-based posting and for the taking of personality quizzes. Our topic-based posting system is called the Digital Sash (Valentine, Leyva-McMurtry, Borgos-Rodriguez, \& Hammond, 2016). The Digital Sash provides simple sketch- or writing-based tasks for users to complete. Upon completion of the tasks, users earn a

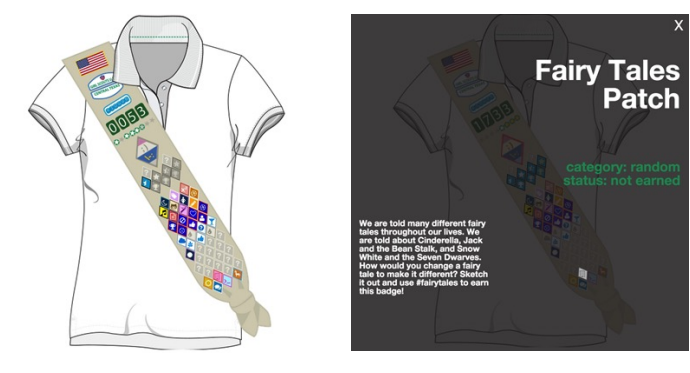

Figure 2: Complete view of the Digital Sash and the Digital Sash in explore mode.

digital badge. Our rewards system takes the form of a Girl Scout sash because the audience for our initial deployment is a local Girl Scout council (more deployment details follow in the next section). The artwork for such an online reward system could take many specialized forms, but the underlying system that makes suggestions for post topics and rewards users for completing the tasks as described is universal. Figure 2 displays screenshots of how a user might explore the badges available to be earned and the instructions for earning them. Badges that are in color have been earned and badges in grayscale are yet to be earned. The example in Figure 2 displays the Fairy Tales badge. The instructions for this badge encourage users to add a new twist to an old fairy tale. To earn the badge, users should 
illustrate their twists with a sketch and use \#fairytales (the hashtags allow the system to automatically award badges). The user whose Digital Sash is shown in Figure 2 (we will call her Mackenzie) earned the Fairy Tale badge with the post shown in Figure 3. Mackenzie sketched Snow White refusing the poisoned apple offered by the evil queen and annotated Snow White with the words, "LOL, Nope." Over a period of 4 weeks following a user's registration on KidGab, KidGab releases approximately 45 badges (one or two badges per day) that can be earned through the procedures described above. $^{3}$

The second of the social networking affordances especially relevant to this study is a continually-increasing collection of whimsical personality quizzes authored for the purpose of entertainment (not for purposes of scientific personality analysis). These quizzes are simple radio-button web forms with themes like "Which team sport should you play?", "Which Harry Potter pet should you bring to Hogwarts?", "What new look should you try on your

3 Note that a badge earnable by one girl may not yet be earnable by another. Badges are automatically released to each user according to a standard preset schedule that begins the day a girl registers. hair?", or "Which Pokémon are you?". Based on the choices in the quiz, users receive different results. For example, the selections chosen in the "Which Harry Potter pet should you bring to Hogwarts?" quiz, shown in Figure 4, led to the result "Owl." A user can choose to post her results to her wall using the blue button beneath her results. Posted quiz results appear on the user's wall in the style shown in Figure 4. At the time of the data analysis described here, 31 quizzes were available for users to take and explore. We attempt to author and release at least one new quiz per week.

Participant Considerations

This work focuses on girls for a number of reasons. First, although early studies on cyberbullying have suggested that cyberbullying is more common among boys (as victims and perpetrators) ( $\mathrm{Li}$, 2006), more recent studies have shown that girls are more likely than boys to be victims (Wang, Iannotti, \& Nansel, 2009), in particular when the age range in the study is limited to middle school students (Kowalski \& Limber, 2007). KidGab not only offers a safe space for girls to participate in social networking, but also teaches them digital citizenship through engaged activities. Second, research has shown that among preadolescents, girls are more interested in social networking than boys

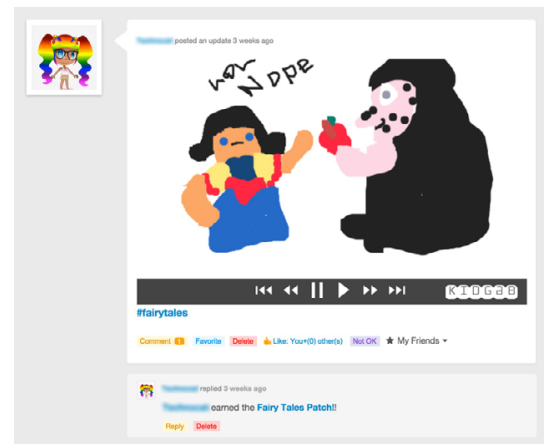

Figure 3: Mackenzie's response to the Fairy Tales badge described in Figure 2.

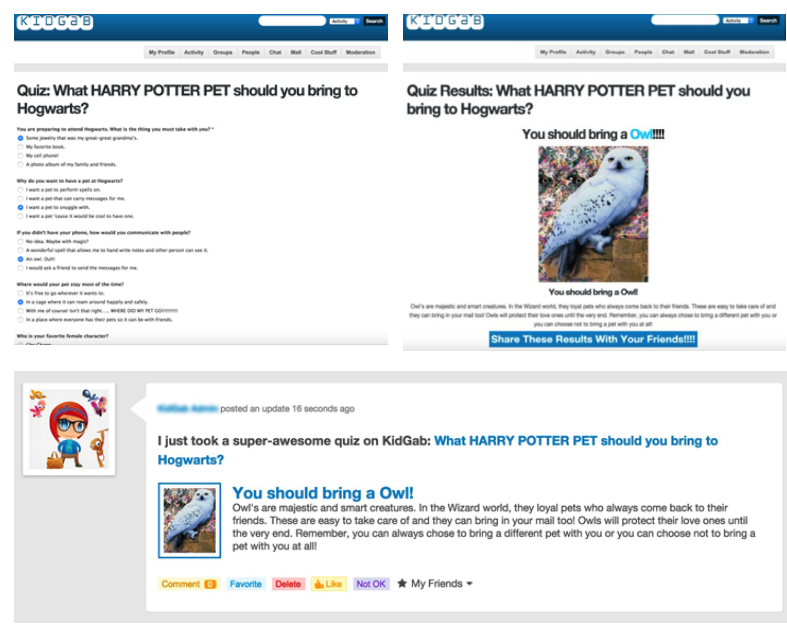

Figure 4: Screenshots of a quiz, quiz results, and a quiz post. 
(Rideout, 2015). KidGab takes strategic advantage of this interest while allowing girls to explore their identities. This is important since studies have shown that identity exploration is a central component of adolescent girls' online behavior (Mazzarella, 2010). KidGab offers an arena to understand how girls in a younger age bracket explore their identity online. Finally, there is a glaring disparity between the number of girls versus boys engaged in the Science, Technology, Engineering, and Mathematics (STEM) fields (Kekelis, Wepsic Ancheta, \& Heber, 2005). A social network for girls where they are able to create, as opposed to only share and post information, has the potential to attract girls at a young age to the STEM fields.

For initial deployments of KidGab, we chose to engage an existing community of active and connected children, the Girl Scouts organization with whom we have a collaborative history.

Ethical Considerations of Consent/Assent

Consent from parents and assent from girls are vital to adhere to both United States federal laws and the strict standards of research integrity set by ourselves and our university. The informed consent/assent process for this research includes two forms. First, parents must read and sign a threepage consent form outlining expectations of the participants, the types of data we will collect, our data management plan, a release to record video, the minimal risks involved with participation, and the benefits of participation to the parents, girls, and society. Second, girls receive and must sign a one-page assent document explaining the project, participant expectations, and data collection procedures. Researchers are available in person, by phone, and by email to answer any consent/assent questions from either guardian or girl. Both forms have been approved by our institutional review board and are subject to annual review.

\section{Data Collection}

In keeping with the larger goals and research objectives of the KidGab project (not specifically addressed in this paper), all girls that join KidGab first partake in a 4-hour workshop led by our research team. The workshops teach skills for safe and healthy digital friendships to groups of 5 to 25 girls aged 7 to 12 years. The workshop curriculum includes a hands-on, guided tour of KidGab (users almost always have not participated on the site prior to the workshop). Following the workshops, we encourage the Girl Scouts to use KidGab as a tool to grow and improve the friendships they kindled with other girls at the workshops.

In March 2015, we deployed KidGab to the first cohort of Girl Scouts. In the seven months between the first deployment and the time we conducted the analysis presented here, we engaged 13 other cohorts for a total of 214 Girl Scout users. Beginning in June 2015, upon approval from our institutional review board, we opened registration to any Girl Scout who provided an active Girl Scout membership number and provided online signatures for consent/assent. The age distribution of all of our participants can be seen in Figure 5. Occasionally,

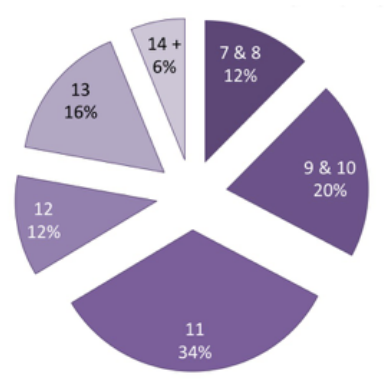

Figure 5. Age distribution of the participants: Percentage of users by age. 


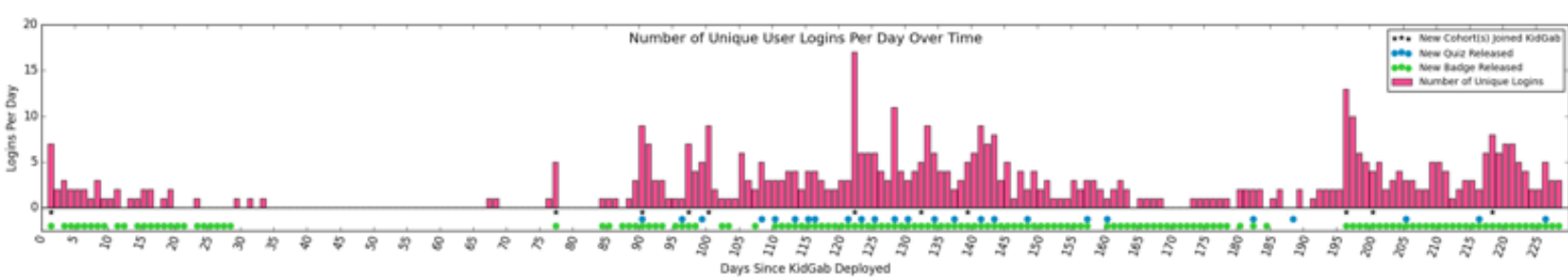

Figure 6: Distribution of activity throughout the study.

Unique users who logged in to KidGab each day. Note

that all zero-activity days and day 197 were removed

from the analysis to eliminate the potential for skewed

results due to outliers.

girls up to age 16 opted to participate in the workshops, but were rarely active on KidGab thereafter.

Following the workshops, we encouraged online participation on KidGab through emailed notifications of both badge releases and quiz releases. Our results show that approximately $37 \%$ of the participants logged in to KidGab following the workshop. We call the users that return to KidGab following the workshops returning users. In this analysis, we study the behavior of only these returning users (80 users), because the data collected from the in-workshop activities of the non-returning users ${ }^{4}$ could skew our results by including potentially misleading activity quantities on workshop days.

Each datapoint in our analysis represents a single day of deployment on KidGab. For each day, we count activities and artifacts that occurred on that day. The days range from 1 to 228. Day 1 trans-

4 In informal interviews with users who choose not to return to KidGab, users expressed regrets such as a lack of Internet access and a schedule too full of school and other activities to dedicate time to maintaining their profiles. We suspect others choose not to return for a lack of intrinsic interest in the topic; the girls may have attended the workshops by their parents' or troop leaders' volition. lates to March 8, 2015. Figure 6, which shows the number of unique users that logged in to KidGab on each of the 228 days of the study, provides a snapshot of the distribution of activity experienced throughout the study. To eliminate outliers with the potential to skew our analysis, we removed all days with zero activity (66 days) and days with excessive surges of activity (1 day). On twelve days, we deployed KidGab to new users in our workshops and suspected that the increased activity might skew our results. However, we found no significant differences between our results sans workshop days and our results including them. Therefore, we included workshop days in our analysis. In the 161 days included in our analysis, our returning users logged in 1023 times and authored 1418 posts, 309 comments, and 1044 likes.

Though each girl and the activities she completes per day are by nature unique, an average daily session per user ${ }^{5}$ includes approximately 1.99 logins, 2.43 posts, 0.55 comments, 1.51 quizzes taken, and 0.82 badges attempted. These values, their standard deviations, and similar values

5 Daily-session averages were calculated using the following formula: $\quad \frac{\sum_{1}^{S} \text { activity count of user in day session }}{\text { number of day sessions, } \mathrm{S}=518}$ 


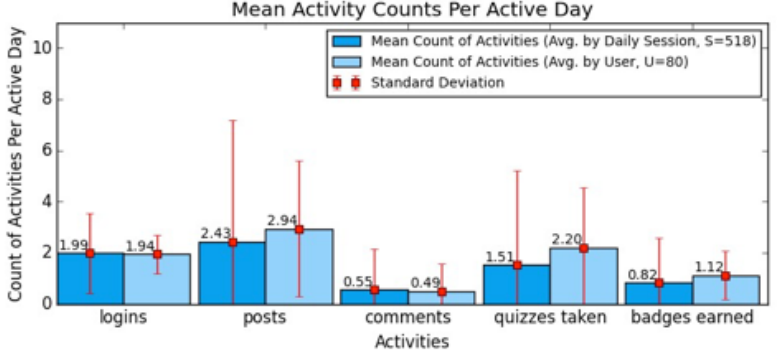

Figure 7: Usage statistics representing the average activities completed by a user on an active day. averaged by user ${ }^{6}$ (instead of by user-session) can be seen in Figure 7. To ensure a few users do not significantly skew our results, as may be suspected based on previous research indicating power-law distributions of user activity online (Broder et al., 2000; Kumar, Raghavan, Rajagopalan, \& Tomkins, 1999), we duplicated all of our analyses on a dataset excluding our most-active $10 \%$ of users. The results of these analyses revealed no differences in conclusions, save one minor statistic noted in the Results section below. All 80 users were therefore included in the presented analysis.

We record nearly every activity a user completes on KidGab, including time and date as well as other relevant metadata for every action, such as successful login, failed login, password change, post authored, comment authored, activity liked, activity deleted, avatar changed, theme changed, profile updated, quiz taken, and badge earned. We used relevant subsets of this usage data to conduct the analysis discussed here.

6 User-based averages were calculated using the following formula: $\frac{\sum_{1}^{U} \frac{\text { total activity count of user }}{\text { number of day sessions of user }}}{\text { number of users, } \mathrm{U}=80}$
Data Preprocessing: Coding and Labeling

Because two of our hypotheses center around the concept of identity-related self-presentations on KidGab, we utilized methods of qualitative data coding to identify posts and comments that reference identity. The qualitative codes (identity themes) allow us to analyze what exactly youth are discussing regarding identity, and specifically which themes of self-presentations follow quizzes and badges. All coding procedures were conducted by a single researcher (the first author), whom we will call the coder.

In the first, open-coding stage of preprocessing, the coder read through all posts and comments made by girls on KidGab (parent, researcher, and troop leader messages were not included), making note of the words and expressions used to talk about identity, according to the definition of identity described above. The coder took note of words, expressions, and sketched depictions that described a user's values, symbols, identifications, or experiences that answer the question, "Who am I?" (Larson, 1995; Stern, 2008). Examples of codes identified in this stage include: red hair, gymnastics, usernames as signatures on posts/sketches, 
self-portraits, pets, dreams, and styles of eyeglasses.

During the focused coding stage, the coder refined and focused our open-coding-stage codes into categories. For example, using the sampling of codes above, red hair, eyeglasses, and self-portraits merged into the category appearances. The complete list of categories generated in this step, their descriptions, and example codes can be found in Table 1. Throughout the focused coding step, the coder concurrently labeled whether each post or comment was an attempt to earn a badge. The coder took advantage of the online nature of KidGab and integrated the coding form into KidGab itself (the form was private and visible to the research team only). All codes and labels were stored in KidGab's database for easy cross-querying during the statistical analysis phase.

In theaxial codingstage, thecodernoted that afew categories needed to be merged, namely the desires and possibilities categories. Many posts expressed desires using the language of possibilities. For example, one user posted: "if I could have an superpower it would be TELEKINISES.\#superpower." The post was accompanied by a sketched self-por-

7 All quoted content from KidGab participants is copied verbatim.

The Journal of Media Innovations 3.1 (2016)
Table 1

Themes identified through qualtative analysis of childrens' self-representation of identity on KidGab

\begin{tabular}{|c|c|c|c|}
\hline Theme & Posts & Example Codes Comprising Theme & Theme Descriptions \\
\hline appearances & 262 & $\begin{array}{l}\text { red hair, short, pretty, cute (of a person), } \\
\text { self portraits }\end{array}$ & $\begin{array}{l}\text { Appearance of one's self or another person. (e.g., “@username \#youareawesome } \\
\text { \#loveyourredhair"). }\end{array}$ \\
\hline characteristics & 315 & $\begin{array}{l}\text { funny, sweet, positive, cool (of a } \\
\text { person), places lived, usernames }\end{array}$ & $\begin{array}{l}\text { Personality and demographic characteristics of one's self or another person. (e.g., } \\
\text { "@username \#youareawesome for being so cool and well awesome. You are so } \\
\text { much fun to be around"). }\end{array}$ \\
\hline capabilities & 179 & $\begin{array}{l}\text { gymnastics, triathlon, sewing, swim- } \\
\text { ming, changing the world }\end{array}$ & $\begin{array}{l}\text { Skills and capabilities of one's self or another person. (e.g., "I sewed an apron for my } \\
\text { dad and I entered it in the fair and I got Grand Champion."). }\end{array}$ \\
\hline preferences & 270 & $\begin{array}{l}\text { like, hate, love, favorite, awesome (of a } \\
\text { non-person), cool (of a non-person }\end{array}$ & $\begin{array}{l}\text { Preferences and proclivities of one's self or another person. (e.g., "I love Girl Scouts, flowers, and } \\
\text { friends!"). }\end{array}$ \\
\hline possessions & 358 & have, my, mine, got & $\begin{array}{l}\text { Possessions or defining connections (such as family members and pets) of one's self or another } \\
\text { person. (e.g., "i would hold my lizard but she won't sit on the couch \#lloveanimals"). }\end{array}$ \\
\hline experiences & 204 & $\begin{array}{l}\text { summer camp, vacations, dreams, } \\
\text { memories }\end{array}$ & $\begin{array}{l}\text { Experiences or memories. Codes are sometimes explicitty stated (e.g., "Today I lifted rocks!!! } \\
\text { they were big and heary... it was for our neighborhood's garden's herb spiral!!'!), and sometimes } \\
\text { implied (e.g., "My dad is a good role model because he tells me what's safe to do and how to do it, } \\
\text { like when him and my brother taught me to shoot a gun. \#trolemodel'). }\end{array}$ \\
\hline $\begin{array}{l}\text { desires \& } \\
\text { possibilities }\end{array}$ & 269 & want, wish, hope, could, should, might & $\begin{array}{l}\text { Desires and imagined circumstances of one's self or another person in the future. (e.g., "I have al- } \\
\text { ways wanted a goldfish. If I got a goldffish I would name it Bubbles. My mom said I had a goldfish } \\
\text { when i was } 5 \text { but I don't remember. filloveanimals"). }\end{array}$ \\
\hline another's identity & 163 & $\begin{array}{l}\text { you, she, he, proper names (not } \\
\text { one's own) }\end{array}$ & $\begin{array}{l}\text { The identity of another person. Aways used in conjunction with another theme, for ex- } \\
\text { ample a post might reference another person's characteristics. (e.g., "\#bestfriend my } \\
\text { best friend is someone who is trustworthy and accepts me the way I am. Shes' super } \\
\text { sweet and is always there for me!"). }\end{array}$ \\
\hline $\begin{array}{l}\text { similarities and } \\
\text { differences }\end{array}$ & 129 & $\begin{array}{l}\text { nicest, taller, funnier, different preferences, } \\
\text { variations in skill }\end{array}$ & $\begin{array}{l}\text { Presentations of one's identity as similar to or different than another person's identity. } \\
\text { Always used in conjunction with another theme. For example, a post might reference } \\
\text { similarities and possessions (e.g., "Cool me and you have matching purses"). }\end{array}$ \\
\hline
\end{tabular}

Note. Codes are almost always explicit, rather than implied, unless otherwise stated. 
trait of the girl manipulating purple objects without touching them. The post expressed a desire to have the power of telekinesis, but the author's language was more consistent with the possibilities category. Because of the frequency of such ambiguities between the two categories, the coder merged them into a single theme during the axial coding stage.

\section{Data Preprocessing: Variables}

We base the presented analysis on daily counts of user activities on KidGab. Our variables, therefore, represent the number of times KidGab users engaged in specific activities. The two variables below (we call this group of variables QB variables) measure participatory artifacts created by taking quizzes or attempting badges.

quizzes-posted-per-day This variable is a count of the posts made to a user's wall containing the results of a quiz recently taken. These quiz posts are optional; a girl can take a quiz without posting her results. Occasionally, a girl will post the results of the same quiz multiple times. On day 205, for example, one user took 6 quizzes but posted 286 quiz-result posts. To avoid skewing the results of our analysis, we remove all duplicate quiz-result posts made by a user in a day. There were a total of 368 duplicate posts removed from this analysis.

badge-attempts-per-day This variable represents posts made as attempts to earn a badge. This is not necessarily the same as the number of badges earned in a day. Some badges require multiple posts and occasionally users will err in their first attempt at earning a badge, so they attempt to earn it a second or third time.

Next, we introduce the participation variables, i.e., those which measure the level of active participation on KidGab.

posts-made-per-day This variable represents voluntary posts made by users per day (except the duplicate quiz-result posts mentioned above).

comments-made-per-day This variable represents the voluntary comments made by users per day. Badge-earning announcements, which are automatically added and are stored as comments, were excluded from these counts.

likes-made-per-day This variable represents the "likes" made per day.

total-activities-per-day This variable represents the sum of all previously-mentioned participation variables, plus the count of logins per day.
The following variables are subsets of the participation variables, but specifically relate to the posts that included self-presentations.

identity-posts-made-per-day This variable represents the count of posts made per day that were labeled with one or more of the identity themes (Table 1).

identity-comments-made-per-day This variable represents the count of comments made per day that were labeled with one or more of the identity themes.

total-identity-related-activities-per-day This variable is a sum of the previous two variables.

total-non-identity-related-activities-per-day This variable is a count of posts and comments per day not labeled with any identity themes.

Statistical Analysis

To determine the correlations (if any) of each $\mathrm{QB} /$ Participation and $\mathrm{QB} / \mathrm{Identity}$ variable pair, we calculated the Pearson product-moment correlation coefficient (Pearson's r). To determine the statistical significance of the difference between any two dependent correlation coefficients, we calculated two-tailed Steiger's z tests. 
Figure 8. Pearson $r$ Correlation Coefficients between engagement and identity variables, quizzes-taken-perday, and badges-earned-per-day. Starred column groups have statistically significant differences between coefficients (Steiger's z values).

\section{RESULTS}

There were 755 quizzes taken, 415 quizzes posted, and 472 badge attempts in total. Quizzes taken exceeds badge attempts despite the fact that the first quiz was not released until day 92 of the deployment, and the number of badges available for earning (approximately 45) far exceeds the number of quizzes available for taking (31). In this section, we discuss the correlations between quiz-taking and badge-attempting behaviors and measures of online participation/identity conversation.

To aid in the comprehension of correlations between variables whose names may be difficult to distinguish, we provide a graphical representation of the statistical analyses below in Figures 8 and 9. The column groupings in Figure 8 appear in the order they are described in the text.

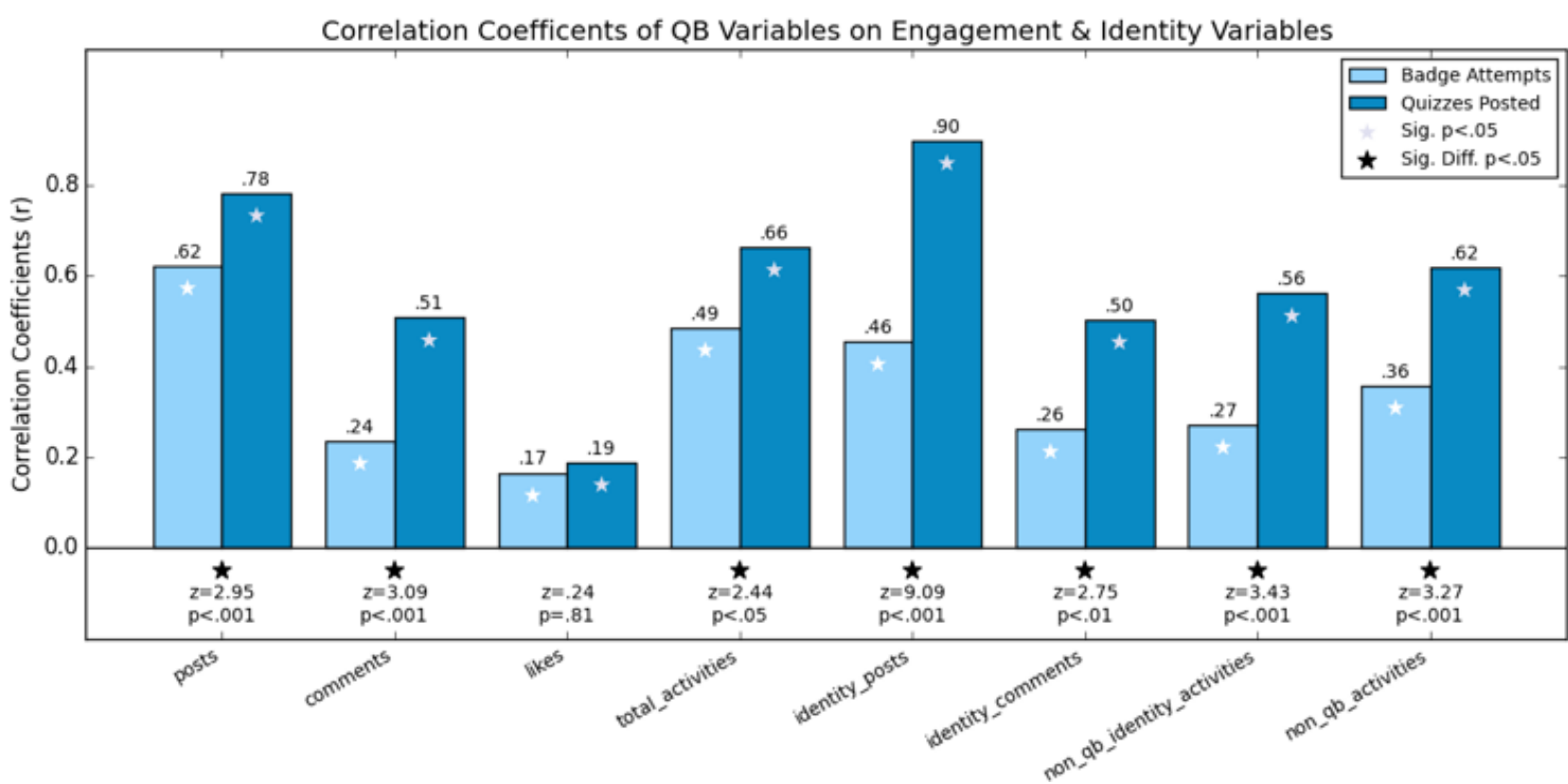

Quizzes vs. Badges: Online Participation

Posts. First, we consider the posting behaviors of our preadolescent users. Posting quiz results is optional and users choose to post their results only about half the time (56\%). Earning a badge, however, always requires a post. The number of posts-made-per-day is correlated with quizzesposted-per-day $(r=.78, \mathrm{p}<$.001) more closely than is the count of badge-attempts-per-day ( $\mathrm{r}=$
$.62, \mathrm{p}<.001)(\mathrm{z}=2.95, \mathrm{p}<.01)$. The increase in coefficients between quizzes-posted-per-day and badge-attempts-per-day (which was not found to be significant when the most-active $10 \%$ of users were removed from the analysis) indicates a weak user preference for posting quizzes over attempting badges. However, these correlations hold little weight, since both quiz-result posts and badge attempts require the user to make a post of some 
kind. Naturally the variables correlate with postsmade-per-day. Comments, on the other hand, are entirely optional.

Comments. There exists a strong correlation between the variables of quizzes-posted-per-day and comments-made-per-day $(\mathrm{r}=.51, \mathrm{p}<. .001)$. This correlation significantly exceeds that of badgeattempts-per-day $(\mathrm{r}=.24, \mathrm{p}<.01)$. The Steiger's $\mathrm{z}$ test between the quizzes-taken-per-day/comments-made-per-day and the badge-attempts-perday/comments-made-per-day pairing showed a significant difference between the correlations $(\mathrm{z}=$ $3.10, \mathrm{p}<.01)$. This measure is especially powerful because neither badges nor quizzes require commenting. Furthermore, there were more badge-attempting posts than quiz-result posts on which to comment (not to mention 92 days without quizzes at all), and yet users still commented on quiz-result posts more than badge-attempting posts.

Likes and Total Activities. Our analyses show no significant differences in correlations between badge- or quiz-related variables and liking behaviors among our users though the QB variables are individually weakly correlated with likes-madeper-day (e.g. badge-attempts: $\mathrm{r}=.17, \mathrm{p}<.05$; quizzes-posted: $\mathrm{r}=.19, \mathrm{p}<.05)$. However, when considering the sum of activities performed by KidGab users in a day (quizzes, badges, likes, posts, comments, etc.), quizzes-posted-per-day correlates with the total-activities-per-day count $(\mathrm{r}=.66, \mathrm{p}<$ .001) significantly more than does badge-attemptsper-day $(\mathrm{r}=.49, \mathrm{p}<.001)(\mathrm{z}=2.44, \mathrm{p}<.05)$.

To summarize the above paragraphs and analyses, our data shows significant correlations between quizzes-taken-per-day and badge-attemptsper-day for the participation variables. For posts, comments, and total activities, quizzes-posted exhibit significantly higher correlations than badge attempts, meaning that more social engagement occurs on days when more quizzes are taken.

\section{QUIZZES VS. BADGES: DISCUSSIONS OF IDENTITY}

Identity Posts. Posts that include identity-themed self-presentations (identity-posts-made-per-day) are more likely to increase as quizzes-posted-perday increases $(\mathrm{r}=.90, \mathrm{p}<$.001) than when badgeattempts-per-day increases $(\mathrm{r}=.46, \mathrm{p}<.001)(\mathrm{z}$ $=9.09, \mathrm{p}<.001)$. The individual correlations are not surprising, since most quiz and badge posts are considered identity-related.

Identity Comments. Comments, however, as discussed in the previous section, are entirely optional and often reference identity (about $55 \%$ of comments reference identity in some way). Comments coded with one or more identity themes (identity-comments-made-per-day) correlate significantly more with quizzes-posted-per-day $(\mathrm{r}=$ $.50, \mathrm{p}<.001)$ than with badge-attempts-per-day ( $\mathrm{r}$ $=.26, \mathrm{p}<.001)(\mathrm{z}=2.75, \mathrm{p}<.05)$.

Non-Badge \& Non-Quiz Activities. To remove the direct impact of quiz posts and badge attempts from posts and comments, we tested counts of nonquiz- and non-badge-related activities (non-QB activities). Following the trend, quizzes-posted-perday correlates $(\mathrm{r}=.56, \mathrm{p}<.001)$ significantly more than badge-attempts-per-day $(\mathrm{r}=.27, \mathrm{p}<.001)(\mathrm{z}$ $=3.43, \mathrm{p}<.005)$ for identity-related non-QB activities. The results are similar for the total-nonQB activities, which can be but are not necessarily identity-related. Also, quizzes-posted-per-day correlates $(\mathrm{r}=.62, \mathrm{p}<$.001) significantly more than badge-attempts-per-day $(\mathrm{r}=.36, \mathrm{p}<.001)(\mathrm{z}=$ $3.27, \mathrm{p}<.001)$. These results indicate that as both badge-attempts and quiz-result posts increase, participatory activities (not including those posts) 
Figure 9. Pearson r Correlation Coefficients between identity themes, quizzes-taken-per-day, and badge-attempts-per-day. Starred column groups have statistically significant differences between coefficients (Steiger's z values).

also increase significantly. However, quiz-result posts are associated with a sizably larger participatory increase than badge attempts.

Activities in Identity Themes. Specific identity theme activity variables (activities labeled to reference at least one of the identity themes) likewise show a tendency to correlate more with quizzesposted-per-day than with badge-attempts-per-day. All nine identity themes correlate significantly with quizzes-posted-per-day $(r=.22, \mathrm{p}<.05)$. Only five

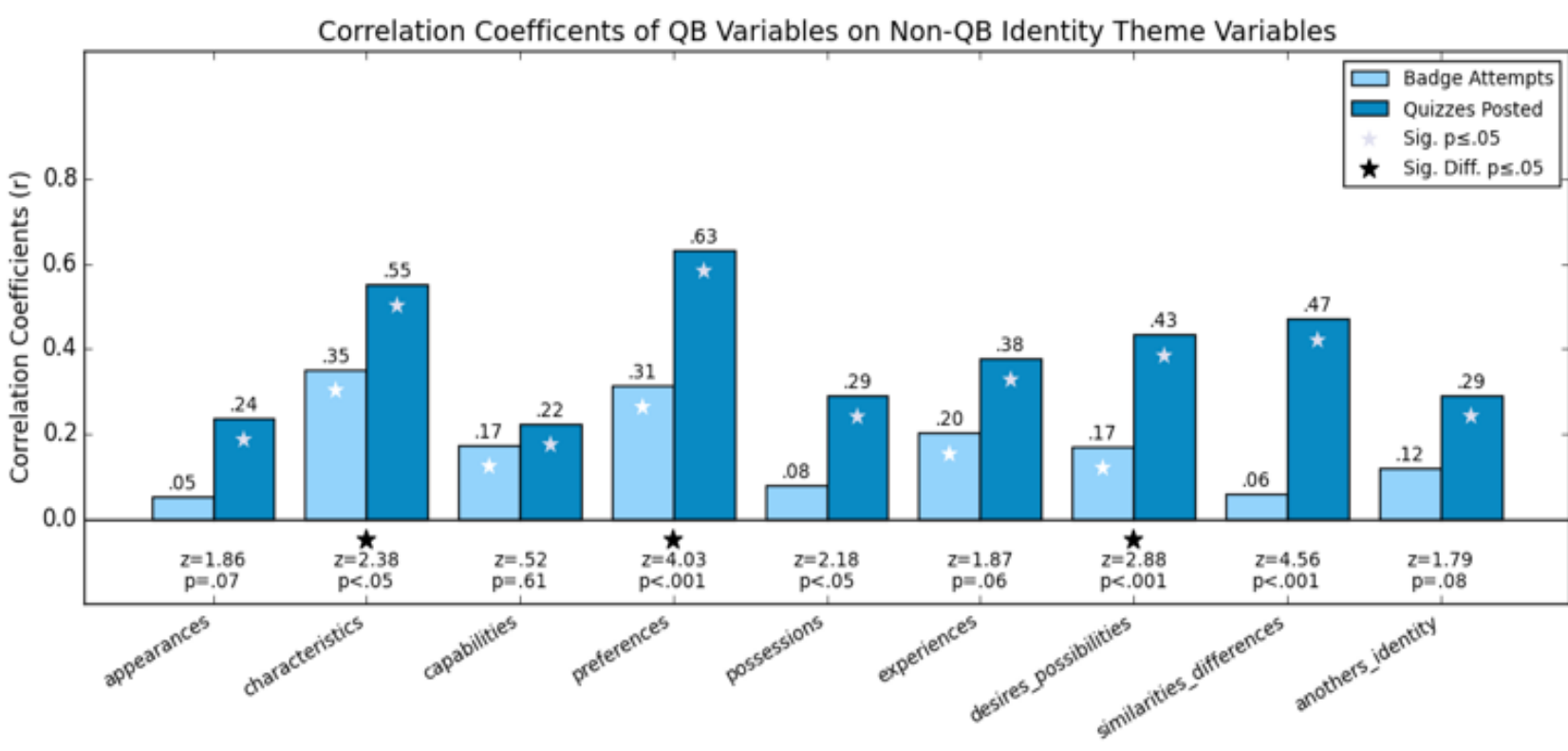

of the nine identity themes correlate significantly with badge-attempts-per-day. Quiz posts correlate with every identity theme more than badge attempts, but only significantly more for three identity themes. Two-tailed Steiger's z tests require both correlations being compared to be significant, making this number (3 out of 9) misleadingly low. The greatest disparity between quiz-posting/ badge-attempting and identity-theme variable correlations was found for the Similarities and Differ- ences theme (quizzes-posted-per-day: $\mathrm{r}=.47, \mathrm{p}<$ .001; badge-attempts-per-day: $\mathrm{r}=.06, \mathrm{p}=.45$ ). Specific correlation coefficients ( $r s$ ) for all identity theme variables and the QB variables can be seen in Figure 9.

In summary, self-presentation activities generally adhere to the trends identified in the online participation analysis above. Posts and comments cantly with both quizzes-taken-per-day and badgethat contain themes of identity correlate signifi- 
attempts-per-day, but correlate significantly more strongly with quizzes-taken-per-day. When we omitted the posts and comments that directly attempt to earn badges or share quiz results, the resulting subset of activities still correlated stronger with quizzes-taken-per-day than with badge-attempts-per-day for both the total-non-QB activities and the non-QB activities that reference identity. Among the identity themes, quizzes-posted-perday correlated significantly with all nine themes, and badge-attempts-per-day correlated with only five themes.

\section{DISCUSSION}

Here, we revisit our four hypotheses and position our results within the (limited) existing literature surrounding youth and their participatory behaviors with digital media.

\section{Hypothesis 1}

Firstly, we hypothesized a significant positive correlation between personality quizzes and online participation on KidGab. Our data revealed that quizzes-posted-per-day correlates highly with posts-made-per-day, comments-made-per-day, and total-activities-per-day. The contribution of our results in regard to this hypothesis is twofold. First, though other researchers have anecdotally mentioned that adults and youth alike enjoy taking personality quizzes (boyd, 2008; L. Clark \& Çalli, 2014; Willett, 2008), this work provides significant quantitative evidence of the popularity of this feature in social networks, particularly for girls in our age range of 7-12 years. The second contribution of our findings in relation to this hypothesis is that taking quizzes correlates positively and significantly with overall participation on KidGab. Though we have not shown that taking quizzes causes increased participation, our evidence of correlation leads us to speculate that this may be the case. In future work, we intend to study whether the quiz taking/posting behavior occurs before each of the other activities in a session (thus building a quantitative base for the study of causation) as well as perform qualitative interviews and focus groups with KidGab users to understand their quizinduced motivations. The confirmation of this hypothesis, though the simplest in this work, lays the foundation work for $\mathrm{H}_{2}, \mathrm{H}_{3}$, and $\mathrm{H}_{4}$.
Hypothesis 2

Secondly, we hypothesized that there exists a significant yet weaker positive correlation between badges and social engagement. Similarly to quizzes, we found that badge-attempts-per-day do correlate significantly with posts-made-per-day, commentsmade-per-day, and total-activities-per-day, but the correlations were significantly weaker than those with quizzes-posted-per-day. Confirming the conclusions of boyd (2008) and Stern (2008), posting about culturally relevant topics (and thus earning badges) is indeed a popular pastime among girls on KidGab. The girls in our study on average posted .82 badge-attempting posts per session-day. However, the rate of participatory decline (correlation of daily participation rates to days-since-cohortreleased) was found to be significantly stronger in the number of girls attempting badges than in the number of quizzes posted per day (participatory decline for badge attempts: $\mathrm{r}=-.39, \mathrm{p}<.001$; participatory decline for quiz posts: $\mathrm{r}=-.21, \mathrm{p}<.01 ; \mathrm{z}$ $=2.05, \mathrm{p}<.05)$. This shows that girls lose interest in badge-attempting significantly sooner than they lose interest in taking and posting quizzes. Our results show that the activities youth desire to participate in change over time, slowly drifting toward the 
activities which elicit more feedback (i.e. quiz posts elicit significantly more comments-made-per-day than badge attempts). With our analysis, we have shown that there is a desire to "write oneself into being” (Addison \& Comstock, 1998, p.129), but that such a desire may be less strong and long-lasting (in terms of overall site participation) than the desire for feedback.

Hypotheses 3 \& 4

Next, we hypothesized that personality quizzes encourage conversations about identity and that badges similarly encourage identity conversation but to a lesser extent. Through our analysis, we found that quizzes-posted-per-day correlates significantly (and significantly higher than badgeattempts-per-day) with identity-themed posting and commenting behavior, even with comments on posts that that are not quiz-results or badgeattempts. We discuss two major arguments for this to be the case: firstly, we discuss risk minimization and secondly, we discuss the advantage of shared experiences.

First, we posit that the transfer of authorship from a girl to the unnamed quiz writer promotes identity-themed online conversation. In the first place (posting comes before commenting), posting quiz results (anonymously-authored short paragraphs "custom"-written about the quiz-taker) is much less risky and more prospectively advantageous to a girl's online identity than posting a similar but self-authored paragraph, like one written to attempt earning a badge. For example, the quiz results shown in Figure 4 regarding what kind of pet a girl should bring to Hogwarts could be quite similar to an attempt to earn the Tails of Love badge, which encourages girls to draw and describe a pet she owns or wants. In our study, 13 girls posted the results of this quiz since its release on day 143 of 228, yet only 10 girls have attempted to earn the badge, despite its initial release on day 9 of 228 , nearly four and a half months prior. Certainly clicking a few buttons to take a quiz is easier than writing a short paragraph, but the published works in support of the acute desire to express one's identity through words (e.g. boyd, 2008; Stern, 2008) indicate that ease might not be a primary factor. Instead, we argue, that our users chose to participate more in quizzes because it reduced the risk for disapproval or unrelatableness, thus maintaining one's membership in the collective conformity (Clarke, 2009; Stern, 2008).
Second, the standardization of the personality quizzes provides girls a shared experience to discuss. Research in both the real and virtual worlds show that people are likely to center conversations around shared interests and experiences (e.g. Erickson \& Kellogg, 2000; H. H. Clark, 1996). Such shared experiences are provided by quizzes but not necessarily by badges. For example, one girl (we will call her Amy) posted her results to KidGab's "Which Disney Pixar Sidekick are you?" quiz. Amy received "Joy, from Inside Out" as her Pixar sidekick result. Another girl commented on the quiz result post, "Cool! I love that movie! Me and you go[t] the same thing!" Because both girls took the quiz and thus had a known shared experience, they were able to begin a conversation about their movie preferences and the similarities in their personalities. This "you got $\mathrm{x}$, I got $\mathrm{y}$ !" commenting behavior is very popular among KidGab's users, as evidenced by the large number of activities referencing similarities/differences in Figure 9 (also note the disparity in correlations between quizposting and badge-earning behaviors). Talking about the shared experience of taking quizzes provides a conversational starting point that may not exist when attempting badges. One girl's mention 
of triathlon training when attempting the Active Girl badge (post about something active you did today) will likely not elicit a response from other girls unfamiliar with the sport of triathlon.

\section{LIMITATIONS}

There are four principal limitations of this work. Firstly, though a sample size of 80 children was sufficient to find relevant results, more users would ensure greater confidence in the generalizability of our findings. Second, our all-female population of participants (further limited by Girl Scout membership) may not reflect the motivations, preferences, and behaviors of all preadolescent youth. KidGab itself, despite its abundance of advantages, has two distinct limitations. The site is under constant development, meaning that micro-improvements and occasional extensive upgrades and feature releases (such as the introduction of personality quizzes) happen at least weekly. This means that each girl experienced KidGab slightly differently, which could potentially impact patterns of usage. Finally, because members of our research team are active participants on the network, their participation is undoubtedly an influence on the community, an influence that cannot be entirely removed for analysis.

\section{CONCLUSION}

In this study, we analyzed the correlations between two little-studied social networking features: personality quizzes and badge-based reward systems on the levels of participation and identity-related artifacts captured by our online social network for preadolescents, KidGab. We found quizzes-postedper-day to correlate more strongly with both online participation and identity conversations, than does badge-attempts-per-day. We have presented many conclusions and contributions, but the following two ideas summarize our main points:

Though youth are indeed interested in self-reflecting via textual compositions, on a daily basis, they partake more in personality-quiz style activities that provide them instant feedback and shared experiences with other users.

Identity-themed conversation tends to follow conformity and sameness of experience. When youth know that they share experiences and clear similarities/differences with other users, they are more likely to engage in conversation.

These contributions provide other researchers a quantitative account of previously singularly qualitative results. Our results provide "micro-level" accounts of what youth actually do on a social network on a daily basis, whereas similarly motivated qualitative studies provide "macro-level" accounts of how and why youth participate in those activities. On a general timeframe, previous studies have suggested that primary motivations for youth to participate in online communities are the desires to self-present, self-reflect, and write one's unique (yet conforming) identity into being (boyd, 2008). However, we found that on a daily basis, youth will participate in the simplest activities that 1) minimize risk of being un-relatable or non-conforming and 2) are more likely to obtain feedback from other users. This may indicate some disparity in what youth say they do and what they actually do, or it may simply indicate that immediate motivations and actions differ from the greater goals and directives youths use to explain their actions.

Though many researchers have published accounts of digital media usage and motivation from the perspective of the youth user, we provide an 
account from the perspective of the digital media platform itself. Bauman and Tatum define social networking as the co-creation of interactive communications, by the users and by the platform (S. Bauman \& Tatum, 2009). Both perspectives are individually valuable but the complete story can only be told when considering both.

\section{ACKNOWLEDGEMENTS}

Many thanks to the Girl Scouts of Central Texas (particularly Emily Magnotta), Katya Borgos-Rodriguez, Angelica Leyva-McMurtry, Jung In Koh, Cassandra Odoula, Hannah Conrad, Andrew Giese, the many Girl Scouts and parents of KidGab, the members of the Sketch Recognition Lab, and the Department of Computer Science and Engineering at Texas A\&M University for their support throughout this project. Many thanks also to Petter Bae Brandtzæg and Asbjørn Følstad for their feedback, support, and patience while preparing this manuscript for publishing. S. Valentine is supported in part by an NSF Graduate Research Fellowship.

\section{REFERENCES}

Abeyrathne, D., Morisawa, Y., Edirisinghe, C., Ranasinghe, N., Karunanayaka, K., Zhu, K., \& Lan, L. (2011). Connected online and offline safe social networking for children. Computers in Entertainment, 9(2), 1-8. doi:10.1145/1998376.1998380

Addison, J., \& Comstock, M. (1998). Virtually out: The emergence of a lesbian, bisexual, and gay youth cyberculture. In J. Austin, \& M. Willard (Eds.), Generations of Youth: Youth Cultures and History in Twentieth Century America (pp. 367-378). New York, NY: NYU Press.

Antin, J., \& Churchill, E. F. (2011, May). Badges in social media: A social psychological perspective. In $\mathrm{CHI}$ 2011 Gamification Workshop Proceedings (pp. 1-4). Retrieved from http://gamification-research.org/ wp-content/uploads/2011/04/o3-Antin-Churchill. pdf

Bauman, S., \& Tatum, T. (2009). Web sites for young children: Gateway to online social networking?. Professional School Counseling, 13(1), 1-10. doi:10.5330/psc.n.2010-13.1

Bauman, Z., \& Vecchi, B. (2008). Identity. Cambridge, UK: Polity Press. boyd, d. (2004). Friendster and publicly articulated social networking. In E. Dykstra-Erickson, \& M. Tscheligi (Eds.), Extended Abstracts of the 2004 Conference on Human Factors and Computing Systems - CHI , 04, (pp. 1279-1282). New York, NY: ACM. doi:10.1145/985921.986043

boyd, d. (2008). Why youth (heart) social network sites: The role of networked publics in teenage social life. In D. Buckingham (Ed.), Youth, Identity, and Digital Media (pp. 119-142). Cambridge, MA: MIT Press.

Broder, A., Kumar, R., Maghoul, F., Raghavan, P., Rajagopalan, S., \& Stata, R. et al. (2000). Graph structure in the Web. Computer Networks, 33(1-6), 309320. doi:10.1016/s1389-1286(0o)ooo83-9

Buckingham, D. (2008). Introducing identity. In D. Buckingham (Ed.), Youth, Identity, and Digital Media (pp. 1-22). Cambridge, MA: MIT Press.

Clark, H. (1996). Using Language. Cambridge, UK: Cambridge University Press.

Clark, L., \& Çallı, L. (2014). Personality types and Facebook advertising: An exploratory study. Journal of Direct Data and Digital Marketing Practice, 15(4), 327-336. doi:10.1057/dddmp.2014.25

Clarke, B. (2009). Friends forever: How young adolescents use social-networking sites. IEEE Intelligent Systems, 24(6), 22-26. doi:10.1109/mis.2009.114 
Donath, J., \& Boyd, D. (2004). Public displays of connection. BT Technology Journal, 22(4), 71-82. doi:10.1023/b:bttj.0000047585.06264.cc

Erickson, T., \& Kellogg, W. (2000). Social translucence: an approach to designing systems that support social processes. ACM Transactions on Computer-Human Interaction, 7(1), 59-83. doi:10.1145/344949.345004

Goffman, E. (1959). The Presentation of Self in Everyday Life. Garden City, NY: Doubleday.

Goodstein, A. (2007). Totally Wired. New York, NY: Saint Martin`s Griffin.

Halavais, A., Kwon, K., Havener, S., \& Striker, J. (2014). Badges of Friendship: Social Influence and Badge Acquisition on Stack Overflow. In R. H. Sprague, Jr (Ed.), Proceedings of the 47th Hawaii International Conference on System Sciences (pp. 1607-1615). Los Alamitos, CA: IEEE Computer Society. doi:10.1109/ hicss.2014.206

Hinduja, S., \& Patchin, J. (2009). Bullying beyond the Schoolyard. Thousand Oaks, CA: Corwin Press.

Inkpen, K., Du, H., Roseway, A., Hoff, A., \& Johns, P. (2012). Video kids: augmenting close friendships with asynchronous video conversations in VideoPal. In E. H. Chi, \& K. Höök (Eds.), Proceedings of the 2012 Conference on Human Factors in Computing Systems - CHI ,12 (pp. 2387-2396), New York, NY: ACM Press. doi:10.1145/2207676.2208400
Itō, M., Baumer, S., Bittanti, M., boyd, d., Cody, R., Herr-Stephenson, B., \& Tripp, L. (2010). Hanging Out, Messing Around, and Geeking Out: Kids Living and Learning with New Media. Cambridge, MA: MIT Press.

Joshi, A., \& Walsh, G. (2011). Twooter: Designing a musical expression tool for use in social networks. In S. Price (Ed.), Proceedings of the 1oth International Conference on Interaction Design and Children IDC ,11 (pp. 169-172), New York, NY: ACM Press. doi:10.1145/1999030.1999053

Kekelis, L., Ancheta, R., \& Heber, E. (2005). Hurdles in the pipeline: Girls and technology careers. Frontiers: A Journal of Women Studies, 26(1), 99-109. doi:10.1353/fro.2005.0013

Kowalski, R., \& Limber, S. (2007). Electronic bullying among middle school students. Journal of Adolescent Health, 41(6), S22-S30. doi:10.1016/j.jadohealth.2007.08.017

Kumar, R., Raghavan, P., Rajagopalan, S., \& Tomkins, A. (1999). Trawling the Web for emerging cybercommunities. Computer Networks, 31(11-16), 14811493. doi:10.1016/s1389-1286(99)ooo40-7

Larson, R. (1995). Secrets in the bedroom: Adolescents private use of media. Journal of Youth and Adolescence, 24(5), 535-550. doi:10.1007/bfo1537055
Li, Q. (2006). Cyberbullying in Schools: A research of gender differences. School Psychology International, 27(2), 157-170. doi:10.1177/0143034306064547 Mazzarella, S. (2010). Girl Wide Web 2.o: Revisiting Girls, the Internet, and the Negotiation of Identity. New York, NY: Peter Lang.

Näsänen, J., Oulasvirta, A., \& Lehmuskallio, A. (2009). Mobile media in the social fabric of a kindergarten. In Proceedings of the 2009 Conference on Human Factors in Computing Systems - CHI ,o9 (pp. 2167-2176), New York, NY: ACM Press. doi:10.1145/1518701.1519031

O‘Keeffe, G., \& Clarke-Pearson, K. (2011). The impact of social media on children, adolescents, and families. Pediatrics, 127(4), 800-804. doi:10.1542/peds.20110054

Posey, J. (2002). They Call Me Kendra: A Crimefighter's Personal Story and Battle Against Online Pedophiles. Culver City, CA: ProStar Publications, Inc.

Rideout, V. (2015). The Common Sense Census: Media Use by Tweens and Teens (Tech. Rep.). San Francisco, CA: Common Sense Media. Retrieved from https://www.commonsensemedia.org/research/ the-common-sense-census-media-use-by-tweensand-teens 
Ringrose, J. (2010) Sluts, whores, fat slags and Playboy bunnies: Teen girls' negotiations of 'sexy' on social networking sites and at school. In C. Jackson, C. Paechter, \& E. Renold (Eds.), Girls and Education 3-16: Continuing Concerns, New Agendas (pp. 170182). Basingstoke, England: Open University Press. Stern, S. (2008) Producing Sites, Exploring Identities: Youth Online Authorship. In D. Buckingham (Ed.), Youth, Identity, and Digital Media (pp. 95-117). Cambridge, MA: MIT Press

Sullivan, D. (2008, January 14). Web 2.o identity theft. Message posted to http://www.realtimewebsecurity. com/type/mt-tb.cgi/593.

Turkle, S. (1995). Life on the Screen: Identity in the Age of the Internet. New York, NY: Simon \& Schuster.

Valentine, S., Leyva-McMurtry, A., Borgos-Rodriguez, K., \& Hammond, T. (2016). The digital Sash: A sketch-based badge system in a social network for children. In T. Hammond, S. Valentine, \& A. Adler (Eds.), Revolutionizing Education with Digital Ink Cham, Switzerland: Springer International Publishing.

Wang, J., Iannotti, R., \& Nansel, T. (2009). School bullying among adolescents in the United States: physical, verbal, relational, and cyber. Journal of Adolescent Health, 45(4), 368-375. doi:10.1016/j. jadohealth.2009.03.021
Wärnestål, P., \& Nygren, J. (2013). Building an experience framework for a digital peer support service for children surviving from cancer. In N. Sawhney, \& E. Reardon (Eds.), Proceedings of the 12th International Conference on Interaction Design and Children - IDC ,13. doi:10.1145/2485760.2485794

Willett, R. (2008). Consumer citizens online: Structure, agency, and gender in online participation. In D. Buckingham (Ed.), Youth, Identity, and Digital Media (pp. 49-69). Cambridge, MA: MIT Press.

Willett, R., Robinson, M., \& Marsh, J. (2009). Play, Creativity and Digital Cultures. New York, NY: Routledge.

Winn, M. (2012). Promote Digital Citizenship through School-Based Social Networking. Learning \& Leading with Technology, 39(4), 10-13. 